\title{
Chondrocytes isolation from hyaline cartilage by continuous monitoring method
}

\author{
${ }^{\star 1}$ Vitalie Cobzac, ${ }^{2}$ Liliana Verestiuc, ${ }^{1}$ Mariana Jian, ${ }^{1}$ Viorel Nacu \\ ${ }^{1}$ Laboratory of Tissue Engineering and Cells Culture \\ Nicolae Testemitanu State University of Medicine and Pharmacy, Chisinau, the Republic of Moldova \\ ${ }^{2}$ Training and Research Center in Tissue Engineering and Regenerative Medicine \\ Grigore T. Popa University of Medicine and Pharmacy, Iasi, Romania
}

Authors' ORCID iDs, academic degrees and contribution are available at the end of the article

${ }^{*}$ Corresponding author - Vitalie Cobzac, e-mail: vitalie.cobzac@usmf.md

Manuscript received February 02, 2021; revised manuscript August 18, 2021; published online December 17, 2021

\begin{abstract}
Background: Articular cartilage has poor regenerative capacities. Numerous cartilage repair techniques are known, including implantation of autologous chondrocytes.

Material and methods: From 18 rabbits pieces of cartilage were harvested from femoral condyle. Minced cartilage was treated with $0.25 \%$ trypsin-EDTA. In the 1 st group $(n=9)$ the cartilage was digested with $0.6 \%$ collagenase in $15 \mathrm{ml}$ tubes by shaking in incubator at $37^{\circ} \mathrm{C}, 5 \% \mathrm{CO}_{2}$. In the $2 \mathrm{nd}$ group $(\mathrm{n}=9)$ digestion was performed in $25 \mathrm{~cm}^{2}$ cell culture flasks placed on the lateral side, monitoring the process under a microscope after 120 minutes. The isolated cells were cultured to a $80-90 \%$ confluence. The chondrocytes were identified using histochemical staining after culturing for 16 days in overconfluence. Results: Chondrocytes isolation in the 1st group lasted a fixed 360 minutes, in the 2 nd group $-140 \pm 10$ minutes. In the 1st group were isolated $9.2 \times 10^{4} \pm 3.1 \times 10^{4}$ chondrocytes with a viability of $85.36 \pm 16.41 \%$, but in the 2 nd group $-1.6 \times 10^{5} \pm 3.4 \times 10^{4}$ chondrocytes with a viability of $98.09 \pm 3.85 \%$. The mean period of cell culture in the 1 st group was $15 \pm 2$ days, in the 2 nd group $-11 \pm 3$ days. In first passage of the 1 st group were obtained $-1.2 \times 10^{6} \pm 4.3 \times 10^{5}$ chondrocytes and in the 2 nd group $-2.92 \times 10^{6} \pm 3.6 \times 10^{5}$ chondrocytes. The secreted extracellular matrix by chondrocytes was stained specifically for cartilaginous tissue. Conclusions: The method used for chondrocytes isolation has a direct impact on the number of isolated cells, their viability, but also upon the culture period and the number of cells obtained during the first passage.

Key words: cartilage, chondrocytes isolation, continuous monitoring.
\end{abstract}

\section{Cite this article}

Cobzac V, Verestiuc L, Jian M, Nacu V. Chondrocytes isolation from hyaline cartilage by continuous monitoring method. Mold Med J. 2021;64(6):13-19. https://doi.org/10.52418/moldovan-med-j.64-6.21.03.

\section{Introduction}

The cartilaginous articular tissue has a poor regenerative capacity [1-4], as a result, the lesion of this tissue can have serious consequences upon the diarthrodial joints, especially the large ones [3, 5-7]. It is known that the number of patients with articular cartilage lesions increases about for a million cases per year [7]. Several nonsurgical and surgical methods (microfractures, allo- or autologous osteochondral tissue transplantation, etc.) have been used as a strategy to repair, or to stimulate the reparation processes of articular cartilage defects, resulting in formation of fibrocartilaginous tissue with reduced mechanical properties and faster wearing compared to hyaline cartilage $[5,8]$. The method for treating cartilage defects is autologous chondrocyte transplantation technique, which currently represents the "Golden Standard" in the regeneration of articular cartilage $[9,10]$. The method is used particularly in treatment of articular cartilage defects in the knee joint. It consists in harvesting pieces of hyaline cartilage from non-weight bearing articular surface of the femur, and release of chondrocytes from it by enzymatic digestion, their culture in vitro and subsequent transplantation in an articular defect, using a three-dimensional collagen matrix $[11,13,14]$, or covering the defect with a periosteal flap and subperiosteal inoculation of chondrocytes $[2,6,7,13,15]$. Being a dynamic process, consisting of many stages, isolation of chondrocytes from articular hyaline cartilage is one of the essential steps of the treatment method. This involves one or more types of enzymes for enzymatic digestion process of cartilage to release the chondrocytes. Their speed depends directly on the enzyme concentration [4, 16-19]. Different periods of time are recommended for enzymatic digestion of cartilage to obtain a sufficient number of cells needed for culture, from 3 to 24 hours, depending on used enzyme combination $[11,16,19]$. Isolation of a large number of chondrocytes allows to reduce the period for cell culture and the number of cell passages in order to obtain a sufficient number of cells for transplantation in a short period of time. Continuous monitoring of chondrocyte isolation process from hyaline articular cartilage has reduced the time period for chondrocyte isolation and obtaining of a larger number of cells for culture. This is very important, because chondrocytes de- 
grade in cells with a fibroblastic phenotype called chondrocyte dedifferentiation. As a result, the quality of synthesized extracellular matrix decreases, becoming fibrocartilaginous $[1,20,21]$.

\section{Material and methods}

In the study were used 18 domestic rabbits $5 \pm 1$ months old, 8 females and 10 males, with an average weight of $3.4 \pm 0.6 \mathrm{~kg}$. To perform the experiments the following solutions and culture media were prepared:

1. Chondrocyte culture media: DMEM culture media (Sigma, UK) - $500 \mathrm{ml}$; fetal bovine serum (VBS) (Lonza, Belgium) - $55 \mathrm{ml}$; fibroblast growth factor (FGF) (Prospec, USA) - $5.5 \mu \mathrm{g}$; transforming growth factor $\beta-2$ (TGF $\beta-2)$ (Prospec, USA) - $550 \mathrm{ng} / \mathrm{ml}$; vitamin C - $13.75 \mathrm{mg} ; 200$ $\mathrm{mM}$ ultraglutamine (Lonza, Belgium) - $5.5 \mathrm{ml}$; penicillin $55000 \mathrm{U}$; streptomycin - $55 \mathrm{mg}$; amphotericin B - $137.5 \mu \mathrm{g}$.

2. Collagenase solution $0.6 \%$ : by dissolution of $600 \mathrm{mg}$ collagenase from Clostridium histolyticum (Sigma, UK) in $100 \mathrm{ml}$ DMEM culture media (Sigma, UK).

3. Tripsin-EDTA solution 0.25\%: Hank's Balanced Salt Solution (HBSS) without calcium and magnesium, with phenol red (Gibco, UK) - 100 ml; EDTA - 37.2 mg (Sigma, Germany); Trypsin from porcine pancreas (Sigma, USA); $0.1 \mathrm{~N} \mathrm{NaOH}$ solution.

All solutions were prepared in sterile conditions under a laminar air flow hood and sterilized by filtering at $0.22 \mu \mathrm{m}$ (Sofra, China).

\section{Isolation and culture of chondrocytes}

Under general anesthesia (with $5 \mathrm{mg} / \mathrm{kg}$ xylazine, 35 $\mathrm{mg} / \mathrm{kg}$ ketamine and $2 \mathrm{mg} / \mathrm{kg}$ diazepam), under sterile conditions, from the non-weight bearing surface of the femoral condyle at the knee joint, pieces of articular cartilage were taken and placed in a $15 \mathrm{ml}$ test tube filled with preheated chondrocyte culture media. The wound was sutured and the animals were isolated in vivarium. The harvested cartilage, under sterile conditions in laminar flow hood (LN 090, Nuve) was washed with warm PBS (HiMedia, India) 3 times. Then the cartilage was minced with a scalpel to fragments of $1-2 \mathrm{~mm}^{3}$ and placed in a sterile $15 \mathrm{ml}$ tube with $5 \mathrm{ml}$ of $0.25 \%$ trypsin-EDTA solution and shaked for 10 minutes in a orbital thermo-shaker (ES-20, Biosan) at 150 $\mathrm{rpm}, 37^{\circ} \mathrm{C}$. The tube was centrifuged for 3 minutes at $50 \mathrm{x}$. After supernatant removal, the cartilage pieces were washed with warm PBS and centrifuged again (fig. 1).

The cartilage pieces were resuspended in $2 \mathrm{ml}$ of $0.6 \%$ collagenase solution [16], with subsequent separation into 2 groups. In the $1^{\text {st }}$ group $(n=9)$ the cartilage pieces with collagenase were transferred to $15 \mathrm{ml}$ tubes, and in the $2^{\text {nd }}$ group $(n=9)$ they were introduced in a $25 \mathrm{~cm}^{2}$ cell culture flasks (Nunc, Denmark) positioned on the lateral side (fig. 2). With the slightly opened cap, the vessels with pieces of cartilage and collagenase were introduced into an incubator (HealForce, Start Cell) at $37^{\circ} \mathrm{C}, 5 \% \mathrm{CO}_{2}$ on a rocker shaker (MR-1, Biosan) and shaked at 20-25 oscillations per minute. In the $1^{\text {st }}$ group, the cartilage pieces were subjected to an enzymatic digestion with $0.6 \%$ collagenase for 6 hours [16].

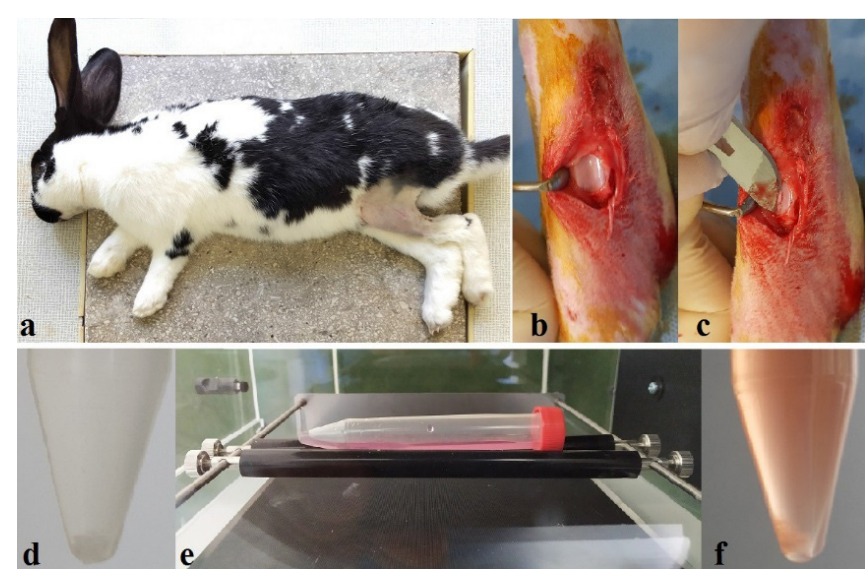

Fig. 1. Articular cartilage harvesting and trypsinization: (a) animal preoperative management,

(b) knee joint opening, (c) cartilage harvesting from the nonweight bearing surface of the femoral condyles, (d) cartilage after mincing and washing, (e) treatment with $0.25 \%$ trypsin-EDTA,

(f) articular cartilage after trypsinization

In the $2^{\text {nd }}$ group, the process was monitored under microscope after 120 minutes of enzymatic digestion every 10-20 minutes, with the interruption of the process when chondrocytes were spread in large number (occupying 50-60\% of field of view), even if the cartilage pieces were incompletely digested. Collagenase digestion was stopped by diluting the solution with $10 \mathrm{ml}$ of preheated PBS. To separate the cells from the undigested cartilage, the solution was filtered through a $70 \mu \mathrm{m}$ pore nylon filter (Sigma, UK) and centrifuged at $170 \times \mathrm{x}$ for 10 minutes. After supernatant removal, the chondrocytes were washed with $10 \mathrm{ml}$ of chondrocyte culture media and centrifuged repeatedly. After centrifugation, the chondrocytes were resuspended in $5 \mathrm{ml}$ of chondrocyte culture media, the cells number and viability were measured with the hemocytometer by trypan blue exclusion method $(1,2,3)$. Chondrocytes were seeded in $25 \mathrm{~cm}^{2}$ cell culture flasks (Thermo Fisher, Sweden) at different densities ranging from $2 \times 10^{3}$ to $8 \times 10^{3}$ living cells per $\mathrm{cm}^{2}$ and incubated at $37^{\circ} \mathrm{C}, 5 \% \mathrm{CO}_{2}$, changing half of the culture media every 2-3 days. At 70-80\% chondrocytes confluence, the cells were detached from the cell culture surface with $0.25 \%$ trypsinEDTA, counted and used by destination: transplantaion, cytotoxicity tests for cryopreservation.

No of cells $/ \mathrm{ml}=$ Average No of cells in $n$ squares $\mathrm{x}$ Dilution fraction $\times 10^{4}(1)$;

Total No of cells $=$ No of cells/ml x Volume (2);

$\%$ living cells $=($ No of living cells $\mathrm{x} 100 \%) /$ Total No of cells (3);

\section{Chondrocytes identification}

From one passage $5 \times 10^{5}$ chondrocytes were taken and placed in two $25 \mathrm{~cm}^{2}$ cell culture flasks in equal number. The cells were cultured in overconfluence for 16 days, with complete changing of culture media every 2 days. After culture in overconfluence the specific cartilaginous extracellular matrix secreted by chondrocytes was identified by 


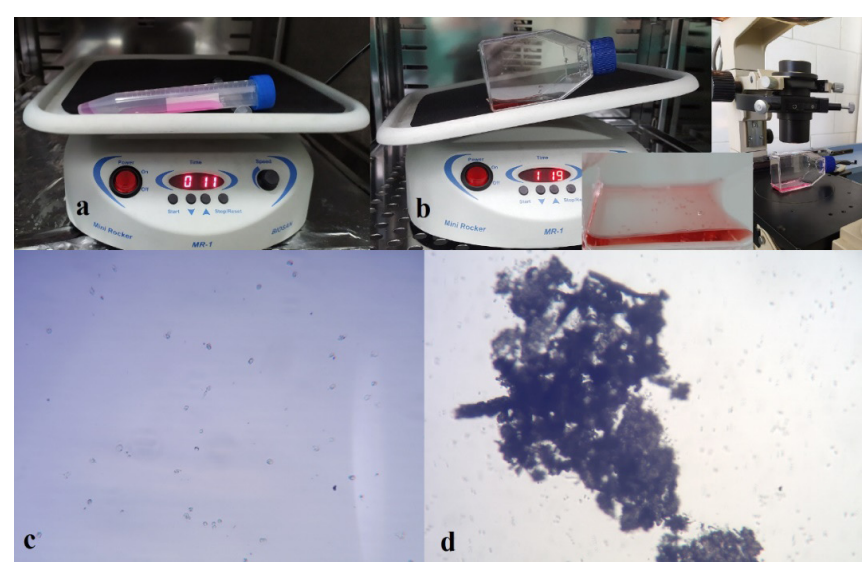

Fig. 2. Enzymatic digestion with $0.6 \%$ collagenase on a rocker shaker in the incubator:

(a) in a $\mathbf{1 5} \mathrm{ml}$ tube for $\mathbf{3 6 0}$ minutes and (b) cartilage enzymatic digestion in a cell culture flask positioned on the lateral side with the possibility of monitoring under a microscope of chondrocytes releasing process, (c) the isolated chondrocytes $(\mathrm{x} 60)$ and $(\mathrm{d})$ the chondrocytes released from cartilage $(\mathrm{x} 40)$

specific staining with Safranin O and Toluidine blue with Fast Green.

As a control group in chondrocytes identification process were used the $3^{\text {rd }}$ passage of primary rabbit bone marrow mesenchymal stem cells (MSC) which were stored at $-85^{\circ} \mathrm{C}$ [22]. The $5 \times 10^{5}$ MSCs were thawed and suspended in $10 \mathrm{ml}$ culture medium consisting of DMEM/F-12 Ham (Sigma, UK) with 10\% FBS (Lonza, Belgium) and antibiotics with antimycotic solution. After pipetting, in two 25 $\mathrm{cm}^{2}$ cell culture flasks were introduced by $5 \mathrm{ml}$ of cell suspension. MSCs were cultured parallely with chondrocytes in incubator at $37^{\circ} \mathrm{C}, 5 \% \mathrm{CO}_{2}$ completely changing the culture media every 1 to 2 days [23].

The staining for chondrocytes identification with Safranin O was realised after removing of cell culture media from the cell culture flask and cells washings with PBS. In cell culture flask were added $5 \mathrm{ml}$ of $0.1 \%$ glutaraldehyde in PBS for $20 \mathrm{~min}$ at room temperature. After 3 consecutive

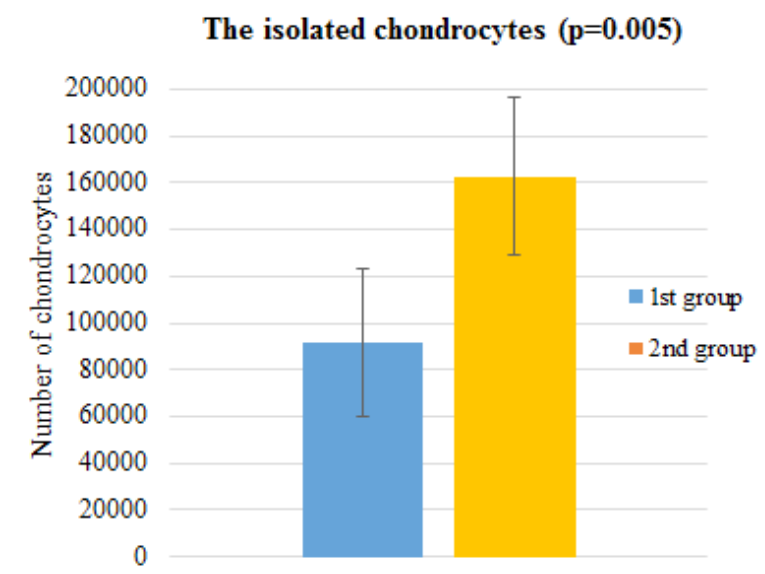

washings with PBS, $3 \mathrm{ml}$ of $0.001 \%$ Fast Green were added for $5 \mathrm{~min}$ and $1 \%$ acetic acid for 10 seconds. The cells were washed repeatedly with PBS and $3 \mathrm{ml}$ of $0.1 \%$ Safranin O solution were added for 15 minutes. After repeated washings, $2 \mathrm{ml}$ of PBS were added for microscopic examination. For Toluidine blue and Fast Green staining, after removing of cell culture media, $3 \mathrm{ml}$ of $0.4 \%$ Toluidine blue were added for 10 minutes. The cells were washed gently 3 times for 30 seconds with $\mathrm{dH} 2 \mathrm{O}$ followed by addition of $3 \mathrm{ml}$ of $0.02 \%$ Fast Green. The cells were washed again 2 times with $\mathrm{dH}_{2} \mathrm{O}$ and other $2 \mathrm{ml}$ of $\mathrm{dH}_{2} \mathrm{O}$ were added for microscopic examination [24].

\section{Results}

As a result of this new method implementation, the number of isolated chondrocytes has increased significantly. The time period of cartilage exposure to collagenase digestion in the $1^{\text {st }}$ group was 360 minutes, whereas in the $2^{\text {nd }}$ group this period varied, having an average of $140 \pm 10$ minutes. As a result, in the $1^{\text {st }}$ group were isolated $9.2 \times 10^{4} \pm 3.1 \times 10^{4}$ chondrocytes, while in the $2^{\text {nd }}$ group, using continuous monitoring, were isolated almost 2 times more cells $-1.6 \times 10^{5} \pm 3.4 \times 10^{4}$ chondrocytes $(p=0.005)$ (fig. 3$)$.

The duration of enzyme exposure, also influenced the viability of the isolated cells, not just their number. After cells counting with hemocytometer by exclusion with trypan blue, in the $1^{\text {st }}$ group was obtained a cell viability of $85.36 \% \pm 16.41 \%$, and in the $2^{\text {nd }}$ group $-98.09 \pm 3.85 \%(\mathrm{p}=$ 0.081 ). An uncritical difference, but in case of isolation of a small number of cells, a low viability may have negative effects on the cellular culture potential. Since the number of viable cells cultured in the first passage was about $7.5 \times 10^{4} \pm 2.1 \times 10^{4}$ and in the $2^{\text {nd }}$ group $-1.6 \times 10^{5} \pm 3.5 \times 10^{4}(\mathrm{p}$ $<0.0001$ ), the time for chondrocyte culture including adhesion to the cell culture surface, multiplication, formation of cellular colonies with a tendency to confluence and reaching a confluence of $70-80 \%$ was different in both groups. In the $1^{\text {st }}$ group the culture period of the first passage was $17 \pm 2$ days, but in the $2^{\text {nd }}$ group $-11 \pm 3$ days $(\mathrm{p}<0.0001)($ fig. 4$)$. As

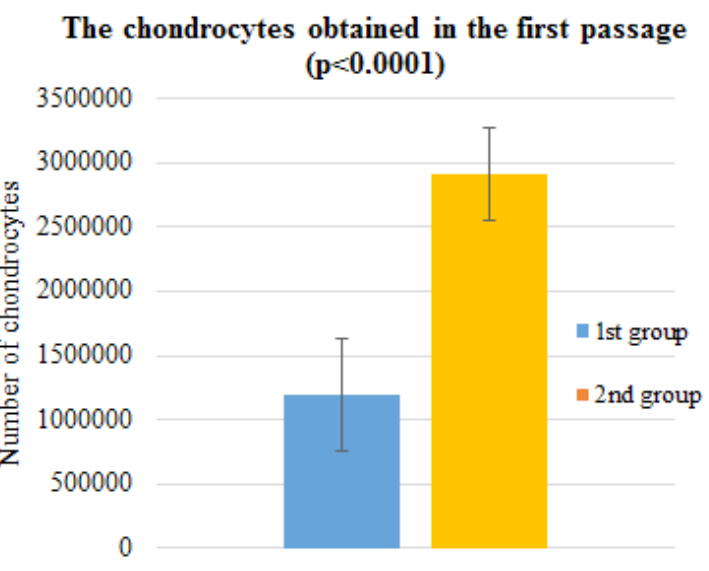

Fig. 3. Comparative presentation of isolated chondrocytes and the number of total chondrocytes obtained in the first passage 


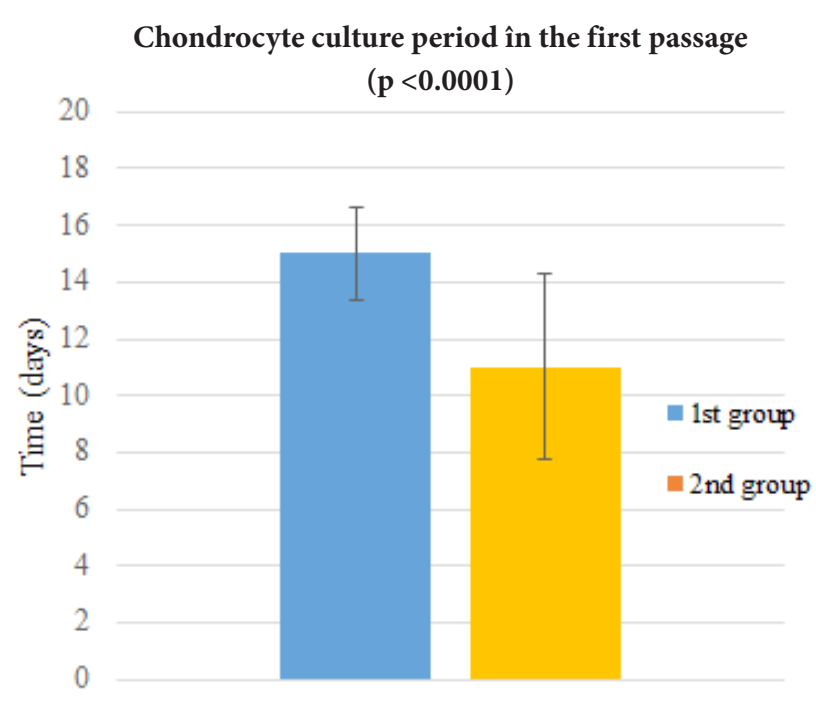

Fig. 4. Chondrocyte confluency during the first passage a result, the number of cells obtained in first passage by both groups was different. In the $1^{\text {st }}$ group were obtained $1.2 \times 10^{6}$ $\pm 4.3 \times 10^{5}$ chondrocytes, and in the $2^{\text {nd }}$ group $-2.92 \times 10^{6} \pm$ $3.6 \times 10^{5}$ cells ( $\left.\mathrm{p}<0.0001\right)$, with a $100 \%$ viability in both groups.

The histochemical staining techniques of the extracellular matrix secreted by chondrocytes during 16 days of culture in overconfluence, allowed to stain the secreted matrix in red-orange with Safranin O, while in the control group (MSC) the staining was absent or poorly expressed. The same is characteristic for Toluidine blue and Fast green staining, where the secreted by chondrocytes extracellular matrix was stained blue-purple, and the staining of extracellular matrix also was absent. This indicates that the isolated cells from hyaline articular cartilage secrete cartilage-specific extracellular matrix and are chondrocytes, but no difference was observed between the stainings of both chondrocytes groups (fig. 5).

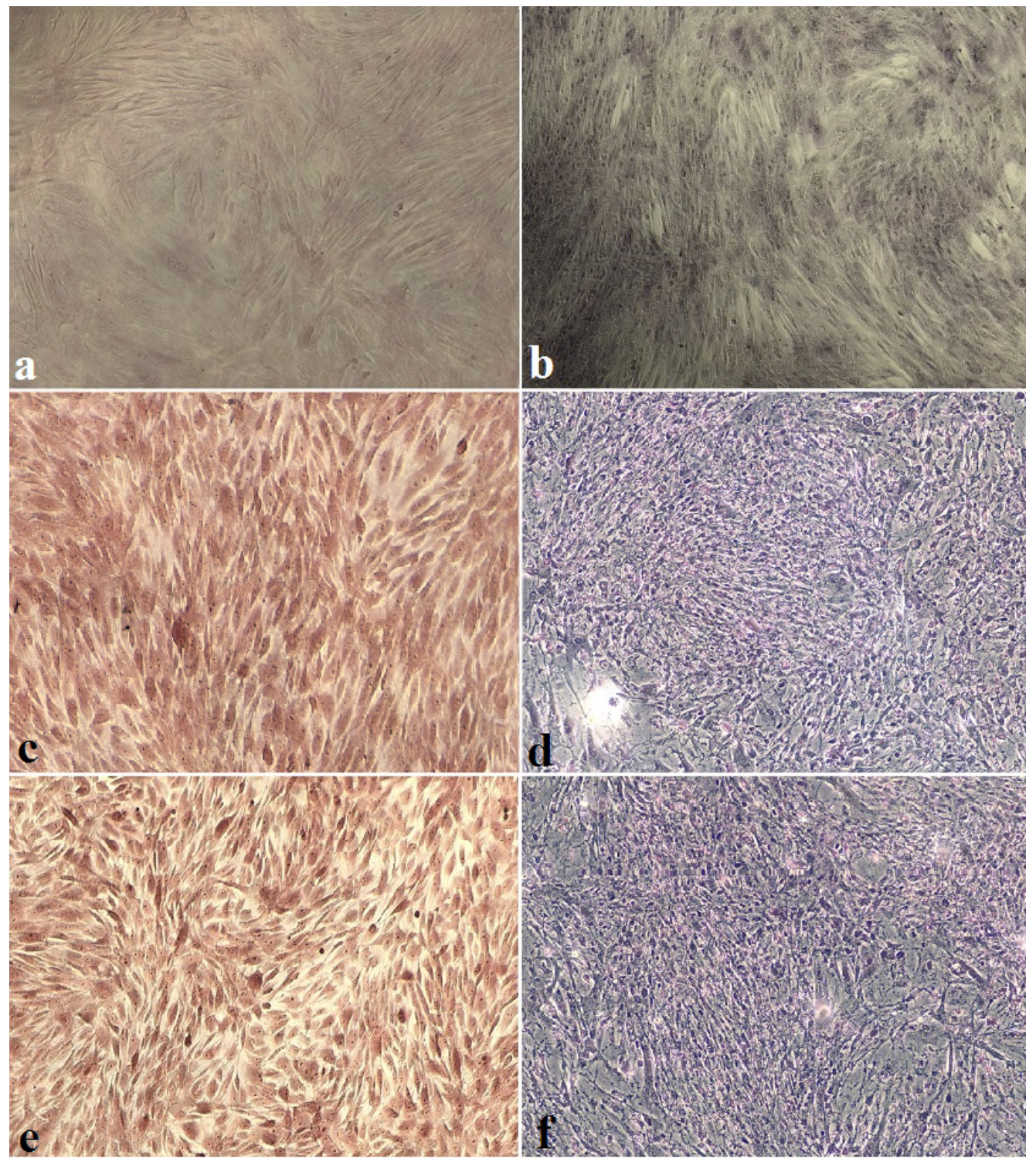

Fig. 5. Cartilage specific staining with Safranin $O$ and Toluidine blue with Fast green (x100): Mesenchymal stem cells - control group $(\mathrm{a}, \mathrm{b})$; the $1^{\text {st }}$ group chondrocytes $(\mathrm{c}, \mathrm{d})$, the $2^{\text {nd }}$ group chondrocytes $(\mathrm{e}, \mathrm{f})$ 


\section{Discussion}

Chondrocytes isolation and culture is an important step for the autologous chondrocyte transplantation process for articular cartilage repair $[2,6,7,9,11-14]$. Chondrocytes can also be used in vitro to test the effects of different substances [25], implants, grafts designed for treatment of cartilage defects or other intra-articular lesions leading to osteoarthritis of the joints $[17,26]$.

The surgical procedure for autologous chondrocyte transplantation has several weak parts, related to both the surgical and the laboratory component. Namely, the laboratory stage ensures the treatment procedure with a sufficient number of chondrocytes, but, in addition to the high risk of contamination and infection of isolated chondrocytes, a negative factor in the culture process to obtain a sufficient number of cells for transplantation is the fibroblastic degradation of chondrocytes, also called chondrocyte dedifferentiation $[1,15,19]$. This dedifferentiation is characterized by changing of chondrocyte shape from round to spindle-like, characteristic for fibroblast, decreased expression of GAGs, COL2A1 and ACAN genes, enhancing the expression of COL1A1 genes. As a result, reducing the synthesis of glycosaminoglycans, type II collagen and aggrecan, but stimulating of type I collagen $[1,19-21]$, which intensifies during cultivation, starting with the second passage [19] and becomes evident after 5 consecutive passages [20]. As a result, reducing the time period for chondrocytes culture in passages is mandatory because it reduces not only the risk of chondrocyte cultures infection, but also the degree of their degradation [27]. To obtain a sufficient number of normal chondrocytes for transplantation, in the literature are described methods of chondrocyte redifferentiation, such as chondrocytes culture on non-adherent surfaces [17], culture on the three-dimensional matrices with their subsequent transplantation [20], culture in condition with a low oxygen pressure [28], mechanical stimulation [29], and utilisation of chondrocyte differentiation factors [30] which we used. Continuous monitoring of chondrocyte releasing process by enzymatic digestion of articular cartilage is aimed to obtain a large number of chondrocytes cultured in a reduced number of passages to obtain the required amount of cells. When a small number of viable chondrocytes is obtained and they are seeded at a density less than $3-3.5 \times 10^{3}$ chondrocytes/ $\mathrm{cm}^{2}$, is observed formation of isolated, nonconfluent chondrocyte colonies as in 7 cases from the $1^{\text {st }}$ group (fig. 6), or stagnation of cellular multiplication. Once the number of cells is sufficient to form uniform cell colonies on a cell culture surface, the number of obtained cells per passage will be higher. The isolated growth of cell colonies dictated by a small number of seeded cells results in occupation of a reduced part of the cell culture surface and, as a result the number of cells obtained per passage is smaller.

Another effective method for chondrocytes obtaining without involvement of enzymatic digestion of articular cartilage is the explant method [14,23]. Since after isolation of chondrocytes from articular cartilage by continuous monitoring permanently remain undigested pieces of cartilage, it is reasonable to combine both methods, which consists in initial release by enzymatic digestion of a large number of condocytes with following utilisation of undigested cartilage as an explant (fig. 7). Also, undigested cartilage pieces
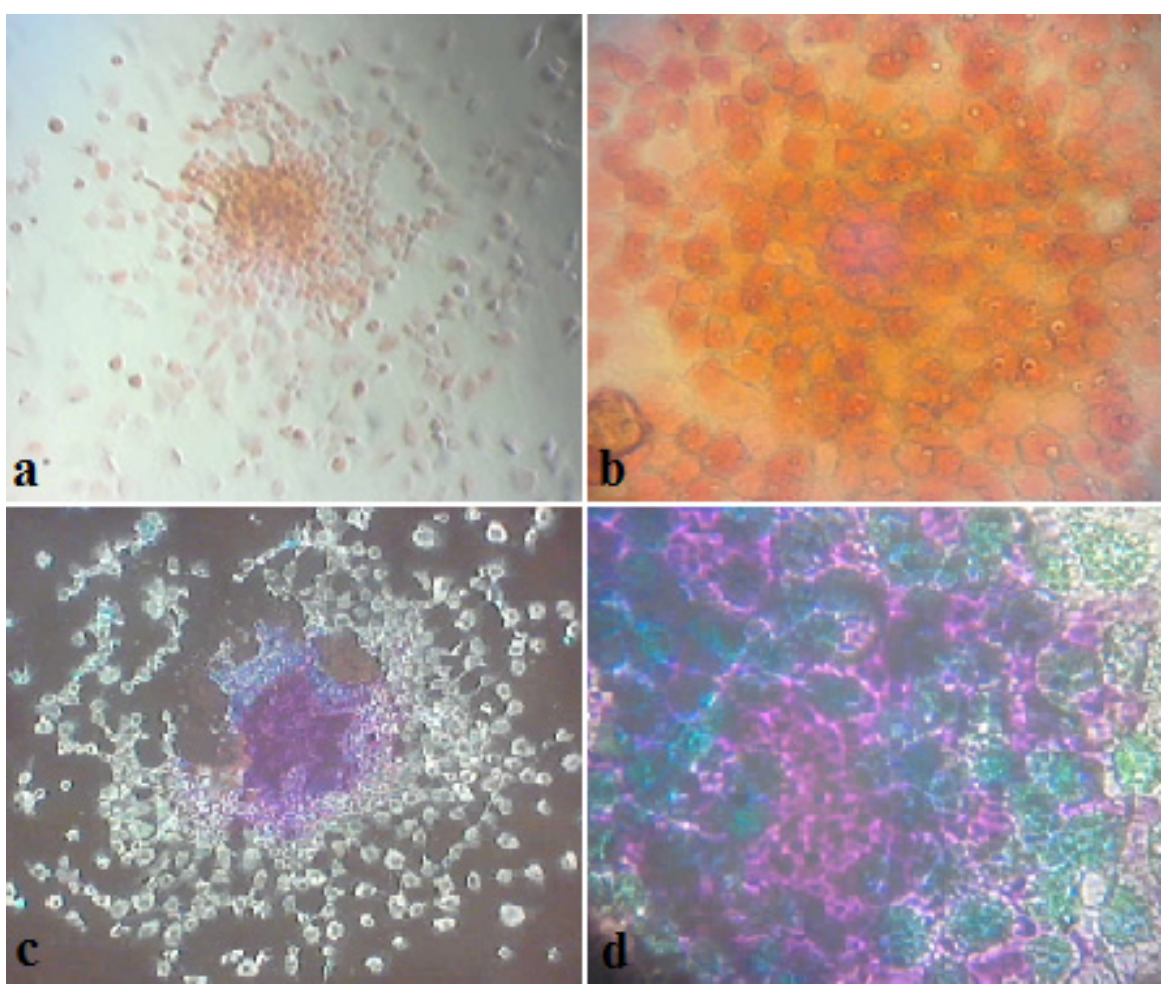

Fig. 6. Isolated cell colony formed as a result of the small number of cultured chondrocytes, stained with Safranin O (a) (x100), (b) (x150) and Toluidine blue with Fast green (c) (x100), (d) (x150) 
may undergo a repeated enzymatic digestion with a fresh dose of collagenase solution.

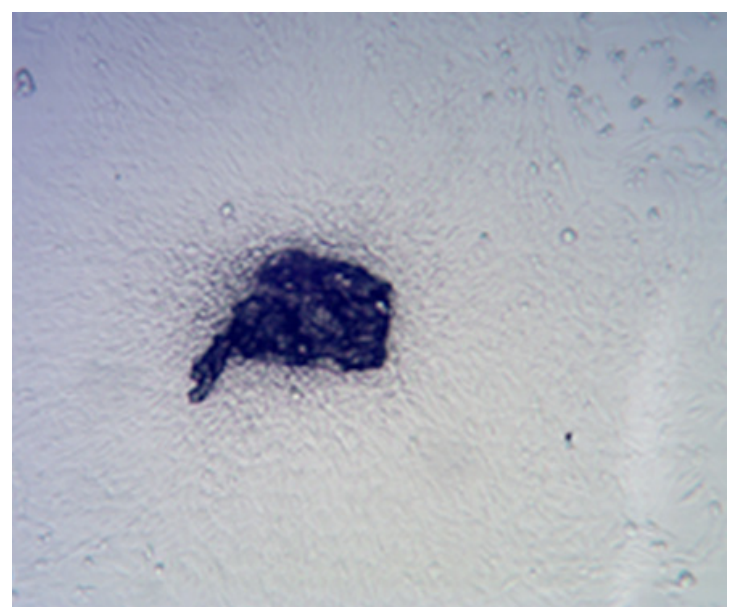

Fig. 7. Chondrocyte colony formation around an explant (x60)

Identification of isolated cells is a mandatory part of cellular isolation and culture process not only for chondrocytes but and for other types of cells [22, 23]. Histochemical methods, such as Safranin O and Toluidine blue with Fast green stainings used for histological analysis of cartilage, are qualitative methods and were sufficient to identify the presence of glycosaminoglycans and proteoglycans specific to cartilaginous tissue in chondrocytes cultured in overconfluence.

\section{Conclusions}

The short period of enzymatic exposure of cartilage during chondrocyte isolation directly influences not only the number but also the viability of isolated cells. Microscopic monitoring of the enzymatic digestion process allowed to isolate approximately 2 times more viable cells $(\mathrm{p}<0.0001)$ in a shorter period of time, and in the first passage the time period for chondrocyte culture was almost one week shorter $(\mathrm{p}<0.0001)$.

Isolation of a large number of viable chondrocytes directly influenced in the first passage duration for cell culture and the number of obtained cells in the first passage. Although there is a segnificant difference between the quantity of isolated chondrocytes in both methods, comparative histochemical examination did not reveal any differences related to the secretion of specific extracellular cartilaginous matrix after culture in overconfluence of the second celular passage.

\section{References}

1. Albrecht C, Tichy B, Nürnberger S, et al. Gene expression and cell differentiation in matrix-associated chondrocyte transplantation grafts: a comparative study. Osteoarthritis Cartilage. 2011;19(10):1219-1227. doi: 10.1016/j.joca.2011.07.004.

2. Jones DG, Peterson L. Autologous chondrocyte implantation. J Bone Joint Surg Am. 2006;88(11):2502-20. doi: 10.2106/00004623-20061100000025.

3. Brittberg M. Autologous chondrocyte transplantation. Clin Orthop
Relat Res. 1999;(367 Suppl):S147-55. doi: 10.1097/00003086-19991000100016.

4. Boopalan PR, Sathishkumar S, Kumar S. Rabbit articular cartilage defects treated by allogenic chondrocyte transplantation. Int Orthop. 2006;30(5):357-361. doi: 10.1007/s00264-006-0120-0.

5. Falah M, Nierenberg G, Soudry M, et al. Treatment of articular cartilage lesions of the knee. Int Orthop. 2010;34(5):621-630. doi: 10.1007/s00264010-0959-y.

6. Ossendorf C, Steinwachs MR, Kreuz PC, et al. Autologous chondrocyte implantation (ACI) for the treatment of large and complex cartilage lesions of the knee. Sports Med Arthrosc Rehabil Ther Technol. 2011;3:11. doi: 10.1186/1758-2555-3-11.

7. Niemeyer P, Albrecht D, Andereya S, et al. Autologous chondrocyte implantation (ACI) for cartilage defects of the knee: A guideline by the working group "Clinical Tissue Regeneration" of the German Society of Orthopaedics and Trauma (DGOU). Knee. 2016;23(3):426-435. doi: 10.1016/j.knee.2016.02.001.

8. Erggelet C, Vavkena P. Microfracture for the treatment of cartilage defects in the knee joint - A golden standard? J Clin Orthop Trauma. 2016;7(3):145-152. doi: 10.1016/j.jcot.2016.06.015.

9. Harris JD, Siston RA, Pan X, et al. Autologous chondrocyte implantation: a systematic review. J Bone Joint Surg Am. 2010;92(12):2220-33. doi: 10.2106/JBJS.J.00049.

10. Salzmann GM, Calek A-K, Preiss S. Second-generation autologous minced cartilage repair technique. Arthrosc Tech. 2017;6(1):e127-e131. doi: 10.1016/j.eats.2016.09.011.

11. Berninger MT, Wexel G, Rummeny EJ, et al. Matrix-assisted autologous chondrocyte transplantation for remodeling and repair of chondral defects in a rabbit model. J Vis Exp. 2013;(75):e4422. doi: 10.3791/4422.

12. Medvedeva EV, Grebenik EA, Gornostaeva SN, Telpuhov VI, Lychagin AV, Timashev PS, Chagin AS. Repair of damaged articular cartilage: current approaches and future directions. Int J Mol Sci. 2018;19(8):2366. doi: 10.3390/ijms19082366.

13. Kon E, Filardo G, Di Martino A, Marcacci M. ACI and MACI. J Knee Surg. 2012;25(1):17-22. doi: 10.1055/s-0031-1299651.

14. Giglio PN, Lizier NF, Levy D, Sobrado MF, Gobbi RG, Pécora JR, Bydlowski SP, Demange MK. Autologous chondrocyte implantation in Brazil. Acta Ortop Bras. 2020;28(3):131-6. doi: 10.1590/1413785220202803226503.

15. Kock L, van Donkelaar CC, Ito K. Tissue engineering of functional articular cartilage: the current status. Cell Tissue Res. 2012;347(3):613-627. doi: 10.1007/s00441-011-1243-1.

16. Yonenaga K, Nishizawa S, Fujihara Y, et al. The optimal conditions of chondrocyte isolation and its seeding in the preparation for cartilage tissue engineering. Tissue Eng Part C Methods. 2010;16(6):1461-1469. doi: 10.1089/ten.TEC.2009.0597.

17. Villar-Suárez V, Calles-Venal I, Bravo IG, et al. Differential behavior between isolated and aggregated rabbit auricular chondrocytes on plastic surfaces. J Biomed Biotechnol. 2004;2004(2):86-92. doi: 10.1155/ S1110724304312039.

18. Oseni AO, Butler PE, Seifalian AM. Optimization of chondrocyte isolation and characterization for large-scale cartilage tissue engineering. J Surg Res. 2013;181(1):41-48. doi: 10.1016/j.jss.2012.05.087.

19. Naranda J, Gradišnik L, Gorenjak M, et al. Isolation and characterization of human articular chondrocytes from surgical waste after total knee arthroplasty (TKA). PeerJ. 2017;5:e3079. doi: 10.7717/peerj.3079.

20. Caron MM, Emans PJ, Coolsen MM, Voss L, Surtel DA, Cremers A, van Rhijn LW, Welting TJ. Redifferentiation of dedifferentiated human articular chondrocytes: comparison of 2D and 3D cultures. Osteoarthritis Cartilage. 2012;20(10):1170-1178. doi: 10.1016/j.joca.2012.06.016.

21. Yao Y, Wang C. Dedifferentiation: inspiration for devising engineering strategies for regenerative medicine. NPJ Regen Med. 2020;5:14. doi: 10.1038/s41536-020-00099-8.

22. Cobzac V, Mostovei A, Jian M, Nacu V. An efficient procedure of isolation, cultivation and identification of bone marrow mesenchymal stem cells. Mold Med J. 2019;62(1):35-40. doi: 10.5281/zenodo.2590011.

23. Jian M, Cobzac V, Mostovei A, Nacu V. The procedure of bone cells obtaining, culture and identification. In: Tiginianu I, Sontea V, Railean $S$, editors. 4th International Conference on Nanotechnologies and Biomedical Engineering. IFMBE Proceedings. Vol 77. Cham: Springer; 
2019. p. 595-599. doi: 10.1007/978-3-030-31866-6_106.

24. Schmitz N, Laverty S, Kraus VB, Aigner T. Basic methods in histopathology of joint tissues. Osteoarthritis Cartilage. 2010;18(3):S113-6. doi: 10.1016/j.joca.2010.05.026.

25. Braniste T, Cobzac V, Ababii P, Plesco I, Raevschi S, Didencu A, Maniuc M, Nacu V, Ababii I, Tiginianu I. Mesenchymal stem cells proliferation and remote manipulation upon exposure to magnetic semiconductor nanoparticles. Biotechnol Rep (Amst). 2020;25:e00435. doi: 10.1016/j. btre.2020.e00435.

26. Cobzac V, Verestiuc L, Jian M, Nacu V. Assesment of ionic and anionic surfactants effect on demineralized osteochondral tissue. In: IOP Conf Ser: Mater Sci Eng. 2019;572:012084. doi: 10.1088/1757899X/572/1/012084.

27. Mandl WE, van der Veen WS, Verhaar JA, van Osch GJ. Seeding densities accelerate cell yield without losing redifferentiation capacity. Tissue Eng. 2004;10(1-2):109-118. doi: 10.1089/107632704322791754.

28. Jeyakumar V, Niculescu-Morzsa E, Bauer C, Lacza Z, Nehrer S. Rediffe- rentiation of articular chondrocytes by hyperacute serum and platelet rich plasma in collagen type I hydrogels. Int J Mol Sci. 2019;20(2):316. doi: 10.3390/ijms20020316.

29. Bao X, Li Z, Liu H, Feng K, Yin F, Li H, Qin J. Stimulation of chondrocytes and chondro-induced mesenchymal stem cells by osteo-induced mesenchymal stem cells under a fluid flow stimulus on an integrated microfluidic device. Mol Med Rep. 2018;17(2):2277-2288. doi: 10.3892/ mmr.2017.8153.

30. Lee J, Lee JY, Chae BC, Jang J, Lee E, Son Y. Fully dedifferentiated chondrocytes expanded in specific mesenchymal stem cell growth medium with FGF2 obtain mesenchymal stem cell phenotype in vitro but retains chondrocyte phenotype in vivo. Cell Transplant. 2017;26(10):1673-1687. doi: 10.1177/0963689717724794.

\author{
Authors' ORCID iDs and academic degrees \\ Vitalie Cobzac, MD, PhD Applicant - https://orcid.org/0000-0002-5010-1163 \\ Liliana Verestiuc, ChED, PhD, Professor - https://orcid.org/0000-0002-3098-8406 \\ Mariana Jian, BioD - https://orcid.org/0000-0001-9352-5866 \\ Viorel Nacu, MD, MPH, PhD, Professor - https://orcid.org/0000-0003-2274-9912
}

\title{
Authors' contributions
}

VC conducted literature review, obtained raw data and wrote the manuscript; LV monitored the experiment and critically revised the manuscript; MJ interpreted the data and drafted the manuscript; VN conceptualized the idea, designed the research and monitored the experiment. All the authors approved the final version of the manuscript.

\section{Funding}

The study was supported by the State Program Project 2020-2023: "GaN-based nanoarchitectures and three-dimensional matrices from biological materials for applications in microfluidics and tissue engineering”. No 20.80009.5007.20. The trial was the authors' initiative; they are independent and take responsibility for the integrity of the data and accuracy of the data analysis.

\section{Ethics approval and consent to participate}

The project was approved by the Research Ethics Committee of Nicolae Testemitanu State University of Medicine and Pharmacy (Protocol No $31,14.12 .2016)$

\section{Conflict of Interests}

No competing interests were disclosed. 